\title{
A Generalized Transducing Phage for a Female Escherichia coli 04
}

\author{
By L. ZUBRZYCKI, JUDITH GREEN AND E. H. SPAULDING \\ Department of Microbiology, Temple University School of Medicine, \\ Philadelphia, Pennsylvania, U.S.A.
}

(Received 1 February 1966)

\begin{abstract}
SUMMARY
The major characteristics of a temperate phage specific, as far as is known, for one strain of Escherichia coli serotype 04 have been described. It is inactivated by ultraviolet light at a rate characteristic of temperate phages, and it is serologically unrelated to the P1, P22 and T phages. This phage (designated $\Phi 04-C F$ ) is short-tailed, contains DNA, is about $55 \mathrm{~m} \mu$, needs no supplemental $\mathrm{Ca}^{2+}$ or $\mathrm{Mg}^{2+}$ for adsorption, shows a latent period of $46 \mathrm{~min}$. and a burst size of 166, and is ultraviolet light inducible. Phage 04-CF can transduce markers to the susceptible indicator strain of $E$. coli (CF 2004-6). The variety of markers transduced indicates that this is another generalized transducing system for $\boldsymbol{E}$. coli. The frequencies of transduction lie between $10^{-6}$ and $10^{-8}$ for different markers, but vary with phage multiplicities. This strain of $E$. coli also acts as recipient in matings with $E$. coli $\mathrm{k} 12$ strains.
\end{abstract}

\section{INTRODUCTION}

A temperate phage was isolated from a mixture of Escherichia coli serotypes 04 and 0127 in a continuous flow culture apparatus (Spaulding, Zubrzycki \& Lanphear, 1964). This phage was subsequently shown to be capable of transducing characters to a strain of $E$. coli serotype 04 . In this communication, we describe some characteristics of this phage and of the transduction system in the female strain of $E$. coli 04 .

\section{METHODS}

Media. Penassay broth (Antibiotic Medium no. 3, Difco) and Trypticase Soy agar and broth (Baltimore Biological Laboratories) were used for routine cultivation of the organisms. Nutrient (Difco) or Penassay broths were used in the adsorption experiments. Semi-solid agar consisted of $0.7 \%$ agar in Trypticase Soy broth. The Davis minimal medium was prepared as described by Lederberg (1950) except that it was solidified with a final concentration of $1.8 \%(\mathrm{w} / \mathrm{v})$ Noble agar (Difco), and sterile solutions of sugars were added to a final concentration of $0.5 \%$. This minimal medium was supplemented, when required, with sterile solutions of amino acids to a final concentration of $30 \mu \mathrm{g} . / \mathrm{ml}$. The buffer for ultraviolet irradiation was the minimal medium without glucose. The phosphate buffer for the adsorption experiment was a solution of the phosphate salts of the minimal medium.

Bacterial strains. Escherichia coli strain CF 2004-6, isolated during a continuous flow (CF) experiment (Spaulding et al. 1964), was used for propagating the phage 


\section{L. Zubrzycki, J. Green and E. H. Spaulding}

04-CF. Its serotype was $04: \mathrm{H} 5$. The $\mathrm{K}$ composition remains undetermined since it reacts with $K 12, K 13$ and $K 53$ antisera on slide agglutination but does not do so in the confirming titration (W. H. Ewing, Communicable Disease Center, personal communication). Mutants of strain CF 2004-6 were obtained by ultraviolet irradiation or by ethyl methane sulfonate combined with the penicillin selection technique (Lederberg, 1950)

The Escherichia coli cF 2004-6 strain was identified as a female by using the w 1895 (Hfr Cavalli) strain of E. coli $\mathrm{x} 12$.

Phage techniques. The procedures used for the one-step growth curves and for determining the adsorption and neutralization constants were those described by Adams (1959). Chloroform was employed in these experiments to inactivate bacteria and release any intracellular phage. High titre $\left(10^{11} / \mathrm{ml}\right.$.) phage stocks were prepared by a modification of a procedure described by Postic \& Finland (1961). Tubes of melted semi-solid agar after seeding with 1000-5000 phage particles and the indicator strain of bacterium were poured onto Petri plates previously layered with 3-4 ml. of unseeded semi-solid agar. These plate cultures were incubated at $37^{\circ}$ overnight after which time there was confluent lysis. They were frozen at $-20^{\circ}$ overnight, slowly thawed at room temperature and the fluid which had separated from the agar was pipetted off. The phage lysates were clarified by low speed centrifugation and stored at $4^{\circ}$ over chloroform.

Spot test for neutralization. Immune sera for neutralization tests were obtained by injecting rabbits with $\Phi$ 04-CF in Freund's complete adjuvant. The phage had been filtered to remove bacterial debris, and the subsequent titre was $10^{10} / \mathrm{ml}$. Six subcutaneous injections of $5 \mathrm{ml}$. each, 3-4 days apart, were given to the rabbits which were bled 6 days after the last injection. The sera obtained from two rabbits were inactivated at $56^{\circ}$ for $30 \mathrm{~min}$. and showed $\mathrm{K}$ values of 288 and $158 \mathrm{~min} .^{-1}$. The rabbit antisera for phages T1, T3, T6, P22 and P1 were obtained from Dr N. Yamamoto (Fels Research Institute, Temple University School of Medicine). Semisolid agar containing appropriate indicator bacteria and enough phage to produce confluent lysis was poured onto a layer of hard agar. $\mathrm{Ca}^{2+}$ to a final concentration of $2 \times 10^{-2} \mathrm{M}$ was added to the agar for the P1 phage system. Loopfuls of antisera diluted in broth were then spotted on the semi-solid agar soon after hardening. The plates were incubated at $37^{\circ}$ overnight. Bacterial growth at the spot where antiserum was placed indicated that neutralization of the phage had occurred.

Ultraviolet irradiation. A 15 W. G.E. germicidal lamp was used as the u.v. source. The lamp was turned on $15 \mathrm{~min}$. before use to help stabilize the output. All ultraviolet experiments were performed under reduced room lighting in order to minimize photo reversion. One-tenth $\mathrm{ml}$. broth dilution of bacteria or phage was added to $10 \mathrm{ml}$. of the clear buffer in a $10 \mathrm{~cm}$. Petri plate which was hand-rotated during irradiation. T2 phage was used as the reference for the ultraviolet intensity under these conditions and at distances of 70 and $50 \mathrm{~cm}$. from the lamp it took 18 and $8 \mathrm{sec}$. respectively to produce $99 \%$ inactivation.

Transduction techniques. Phage 04-CF was added to $24 \mathrm{hr}$ cultures of cF 2004-6 mutants at phage multiplicities of 1 to 4 (unless otherwise indicated). The mixtures were incubated $15 \mathrm{~min}$. at $37^{\circ}$. It had been determined that under these conditions 85 to $99 \%$ of the phage was adsorbed and $50 \%$ or more of the bacteria survived. One-tenth ml. samples were plated on appropriate selective media. After $48 \mathrm{hr}$ 
at $37^{\circ}$ the transductants were scored and the few revertants on the control plates subtracted.

Nucleic acid determination. Phage stocks were filtered, treated with $10 \mu \mathrm{g} . / \mathrm{ml}$. each of DNAse and RNAse at $37^{\circ}$ for $1 \mathrm{hr}$ and clarified by low-speed centrifugation. The phage was then centrifuged at $30,000 \mathrm{rev} . / \mathrm{min}$. for $2 \mathrm{hr}$ in a model L Spinco, resuspended in buffer and clarified by low-speed centrifugation. The nucleic acid was extracted by the hot phenol method (Guthrie \& Sinsheimer, 1963). The diphenylamine and orcinol reactions (Schneider, 1957) were used to detect DNA and RNA respectively.

Conjugation technique. A log phase culture of w 1895 was mixed with a stationary culture of CF 2004-6 at a ratio of $1: 20$. Mating was facilitated by filtering the mixture onto Millipore filters according to the technique of Matney \& Achenbach (1962). After $1 \mathrm{hr}$ incubation the mixture was vigorously agitated in cold saline to break the mating pairs and then plated. Recombinants were scored after $48 \mathrm{hr}$.

\section{RESULTS}

Morphology of the DNA phage. The plaques of $\Phi$ 04-CF on Escherichia coli CF 2004-6 were about $2 \mathrm{~mm}$. in diameter and contained lysogenic survivors. The phage on electron-micrographs appeared to have a very short tail, and was essentially spherical with a diameter estimated to be about $55 \mathrm{~m} \mu$.

The nucleic acid preparation of $\Phi$ 04-CF was negative for RNA by the orcinol reaction when examined with a Spectronic 20 at $660 \mathrm{~m} \mu$ wavelength, but it gave a visibly positive diphenylamine reaction for DNA.

Phage specificity. The bacteria to be checked for susceptibility to phage were inoculated into semi-solid agar which was then poured on to a bottom layer of hard $\operatorname{agar}(1.5 \%)$. A drop of phage stock containing $10^{10}$ or more phage per ml. was spotted onto the lawn of bacteria. The bacteria tested are listed in Table 1. These include strains susceptible to phages P1, P22, T1 through T7, a variety of colicins, and Escherichia coli $\mathrm{K} 12$ strains lysogenic and non-lysogenic for lambda $(\lambda)$, as well as donor and recipient strains. Only $\boldsymbol{E}$. coli strains of serotype 04 were susceptible to $\Phi$ 04-CF by our spotting method, and this susceptibility was evidenced as an area of inhibition similar to that seen when a colicin acts upon a susceptible indicator strain. Phage 04-CF would only plaque and propagate on one strain, CF 2004-6.

$A d$ sorption rates. Log growth cells of bacteria were used to adsorb $\Phi$ 04-CF. These bacteria were also resuspended in nutrient broth, with and without the addition of $\mathrm{Ca}^{2+}$ or $\mathrm{Mg}^{2+}$, and in phosphate buffer. The results, summarized in Table 2, indicate an average $\mathrm{K}$ value of $2 \times 10^{-9} \mathrm{ml}$. min. ${ }^{-1}$. The results also show that the addition of $2 \times 10^{-2} \mathrm{M}^{-\mathrm{Ca}^{2+}}$ or $\mathrm{Mg}^{2+}$ does not increase the adsorption rates. In fact, the $\mathbf{K}$ value in phosphate buffer was comparable to those in nutrient broth with or without the addition of the cations. Phage 04-CF does not adsorb to the following strains : Escherichia coli 0127, Hfr donor к $12(\lambda-)$, Hfr donor K $12\left(\lambda^{+}\right), \mathrm{F}^{-}$recipient $\mathrm{K} 12\left(\lambda^{-}\right)$.

Neutralization. Neutralization tests were carried out as described in the Methods section. The results shown in Table 3 indicate that $\Phi 04-C F$ is not serologically related to the other phages tested.

One-step growth curve. Figure 1 is a typical one-step growth curve. The results of 
three such experiments indicate a minimal latent period about 46 minutes and an average burst size of 166 with a range of 145 to 182 .

Ultraviolet inactivation. Figure 2 is the semilog plot of survival after u.v. irradiation. The slope of inactivation relative to $\mathrm{T} 2$ phage is about 0.05 and to $\mathrm{T} 1$ phage is about $\mathbf{0 . 4}$. This rate of inactivation is similar to that of other temperate phages (Bertani, 1958).

Induction by ultraviolet light. Phage 04-CF can lysogenize Escherichia coli cF 2004-6. This was demonstrated in the following way: cF 2004-6 isolated from the

Table 1. Bacterial strains resistant to phage $\Phi 04-C F$ by the spottesting method

\begin{tabular}{|c|c|c|c|}
\hline & $\begin{array}{c}\text { No. } \\
\text { tested }\end{array}$ & & $\begin{array}{c}\text { No. } \\
\text { tested }\end{array}$ \\
\hline Escherichia coli serotypes & 123 & Serratia marcescens SM6 & 1 \\
\hline Strain $\mathbf{~} 12$ & 22 & Bacillus subtilis 168 & 1 \\
\hline E. coli $\mathrm{B}$ and $\mathrm{B} / \mathbf{r}$ & $\mathbf{3}$ & Salmonella typhimurium LT2 & $\mathbf{3}$ \\
\hline E. freundii & $\mathbf{3}$ & Shigella sonnei & 3 \\
\hline \multirow[t]{2}{*}{ E. $\operatorname{coli} \mathrm{C}$} & 1 & S. flexneri & 1 \\
\hline & & S. dysenteriae 16 & 1 \\
\hline
\end{tabular}

Table 2. Adsorption rates in various media

\begin{tabular}{|c|c|c|c|c|}
\hline \multirow[b]{2}{*}{ Media } & \multirow{2}{*}{$\begin{array}{c}\text { Bacterial } \\
\text { counts } \\
\left(\times 10^{7} / \mathrm{ml} .\right)\end{array}$} & \multirow{2}{*}{$\begin{array}{l}\text { Phage- } \\
\text { bacterium } \\
\text { ratio }\end{array}$} & \multicolumn{2}{|c|}{$\begin{array}{c}\text { Percentage adsorption and } \\
\text { K values } \\
\left(\mathrm{ml} . \text { min. }^{-1}\right)\end{array}$} \\
\hline & & & $5 \mathrm{~min}$. & 15 min. \\
\hline Nutrient broth & $\mathbf{3 \cdot 6}$ & $\mathbf{1} \cdot \mathbf{5}$ & $\begin{array}{c}52 \% \\
4.1 \times 10^{-9}\end{array}$ & $\begin{array}{c}94 \% \\
5 \cdot 1 \times 10^{-9}\end{array}$ \\
\hline Nutrient broth $+2 \times 10^{-2} \mathrm{M}-\mathrm{Ca}^{2+}$ & $\mathbf{3 \cdot 6}$ & $1 \cdot 5$ & $\begin{array}{c}56 \% \\
4.5 \times 10^{-9}\end{array}$ & $\begin{array}{c}87 \% \\
3.7 \times 10^{-9}\end{array}$ \\
\hline Nutrient broth $+2 \times 10^{-2} \mathrm{M}-\mathrm{Mg}^{2+}$ & $3 \cdot 6$ & $1 \cdot 5$ & $\begin{array}{c}52 \% \\
4.1 \times 10^{-9}\end{array}$ & $\begin{array}{c}95 \% \\
5.6 \times 10^{-9}\end{array}$ \\
\hline Phosphate buffer & 5 & $0 \cdot 72$ & $\begin{array}{c}67 \% \\
4.4 \times 10^{-9}\end{array}$ & $\begin{array}{c}92 \% \\
3.3 \times 10^{-9}\end{array}$ \\
\hline Penassay broth* & $7-13$ & $0 \cdot 01-0 \cdot 09$ & $\begin{array}{c}53 \%{ }^{-74} \% \\
2 \times 10^{-9}\end{array}$ & - \\
\hline
\end{tabular}

* The $\mathrm{K}$ value in Penassay broth is an average of five determinations, with the ranges of count, phage multiplicities and percentages adsorbed shown in the table.

Table 3. Results of neutralization by the spot-testing method

\begin{tabular}{ccccccc} 
& \multicolumn{7}{c}{} & Phages \\
Antisera* & T1 & T3 & T6 & P22 & P1 & Ф 04-CF \\
T1 & + & - & - & $\cdot$ & $\cdot$ & - \\
T3 & - & + & - & $\cdot$ & $\cdot$ & - \\
T6 & - & - & + & $\cdot$ & $\cdot$ & - \\
P22 & $\cdot$ & $\cdot$ & $\cdot$ & + & $\cdot$ & - \\
P1 & $\cdot$ & - & $\cdot$ & $\cdot$ & + & - \\
Ф 04-CF & - & - & - & - & - & +
\end{tabular}

* A plus sign indicates neutralization. 
centre of phage plaques was repeatedly subcultured in broth containing $\Phi$ 04-CF antiserum to neutralize free phage, and then re-isolated on agar. Such strains still harbored $\Phi 04-C F$ and were now resistant to the same phage. These lysogenic derivatives of CF 2004-6 could be induced by ultraviolet irradiation to produce Ф 04-CF. Log phase cultures were centrifuged, washed, resuspended in broth, diluted 1/100 in buffer to contain approximately $5 \times 10^{7}$ bacteria/ml., and then irradiated. Appropriate dilutions (determined by trial runs) were made in warm broth for the first and second growth tubes to determine the burst sizes and latent periods.

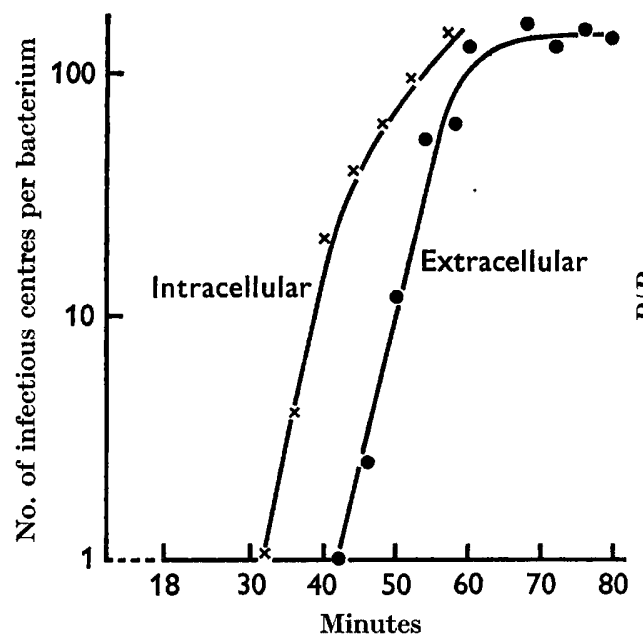

Fig. 1

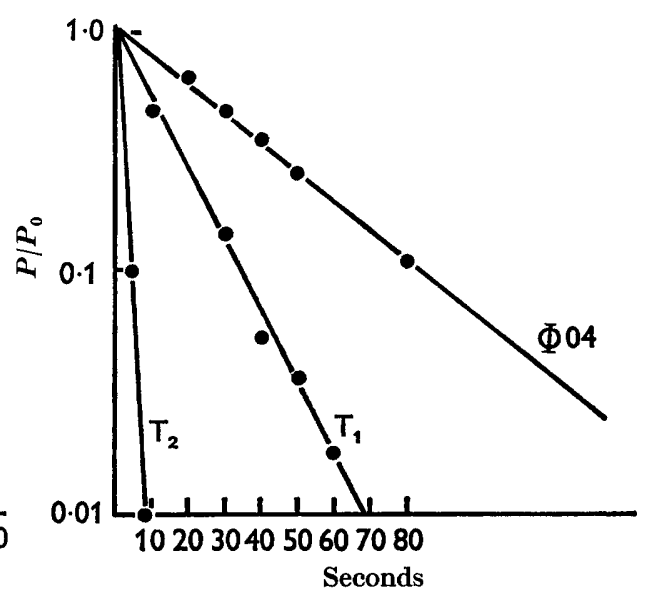

Fig. 2

Fig. 1. A typical one-step growth curve at $37^{\circ}$ showing the intra- and extra-cellular appearance of $\Phi$ 04-CF.

Fig. 2. Survival curves after ultraviolet irradiation at $50 \mathrm{~cm}$. from the lamp.

Table 4. Induction of lysogenic E. coli strain CF 2004-6 upon irradiation with ultraviolet light at $70 \mathrm{~cm}$ distance

(The results in parentheses are from a repeat experiment.)

\begin{tabular}{|c|c|c|c|}
\hline $\begin{array}{c}\text { Ultraviolet } \\
\text { dose }\end{array}$ & $\begin{array}{l}\text { Approximate } \\
\text { latent } \\
\text { period } \\
\text { (min.) }\end{array}$ & $\begin{array}{c}\text { Average } \\
\text { burst } \\
\text { size }\end{array}$ & $\begin{array}{l}\text { Percent } \\
\text { induced } \\
\text { bacteria }\end{array}$ \\
\hline $20 \mathrm{sec}$ & $82-88$ & 152 & 27 \\
\hline $40 \mathrm{sec}$ & 88-94 & $103-(130)$ & $25-(30)$ \\
\hline $60 \mathrm{sec}$ & $88-94$ & $112-(102)$ & $26-(30)$ \\
\hline $80 \mathrm{sec}$ & $94-100$ & $60-(89)$ & $21-(24)$ \\
\hline
\end{tabular}

When a lysogenic broth culture was plated with a phage-susceptible indicator strain, $2-15 \%$ of the bacteria were found eventually to produce phage as evidenced by plaque formation. Since phage was released at widely variable times after plating, the plaques differed markedly in size and were difficult to count. After chloroform treating the lysogenic culture to kill the bacteria, there was an average of about one free phage particle/100 bacteria when determined by plaque count. After ultraviolet irradiation with the doses reported in Table 4, 21-30\% of the bacteria show 
up as plaques. These were large, and uniform in size, presumably because induction had occurred at about the same time. Though the induction percentages were quite constant during the period between $20 \mathrm{~min}$. after irradiation and the end of the latent period, the bacterial colony counts decreased until there were usually fewer than $1 \%$ survivors. With increasing doses of irradiation the minimal latent periods increased and the burst sizes decreased. Weigle \& Delbruck (1951) reported similar shifts in the one-step growth curves and erratic bacterial counts after u.v. induction of Escherichia coli lysogenic for $\lambda$.

Table 5. Comparison of transduction frequencies at various phage multiplicities

Overnight bacterial cultures of a double auxotroph were used and selection was made for methionine transductants on minimal medium containing tryptophan.

$\begin{array}{ccc}\begin{array}{c}\text { Phage } \\ \text { multiplicities }\end{array} & \begin{array}{c}\text { Frequency of } \\ \text { transductants per } \\ \text { phage adsorbed }\end{array} & \begin{array}{c}\text { Number of } \\ \text { transductants } \\ \text { per ml. }\end{array} \\ 0 \cdot 1 & \mathbf{7 \cdot 2} \times 10^{-7} & 145 \\ 1 \cdot 0 & 2 \cdot 2 \times 10^{-7} & 361 \\ 3 \cdot 0 & 4.9 \times 10^{-8} & 240 \\ 10 \cdot 0 & 3 \cdot 2 \times 10^{-8} & 346\end{array}$

Table 6. Transduction of mutant strains of E. coli $C F$ 2004-6

All transductions were run with overnight cultures. The last six were concentrated $10 \times$.

Mutant strains

$$
\begin{aligned}
& \text { tryp }^{-} \text {pro }^{-} \\
& \text {tryp }^{-} \\
& \text {tryp }^{-} \text {leuc- } \\
& \text { tryp }^{-} \text {isol } \\
& \text { tryp }^{-} \text {cys } \\
& \text { (Conc. } 10 \times \text { ) } \\
& \text { tryp }^{-} \text {leuc } \text { arg- }^{-} \\
& \text {phe } \\
& \text { gal } \\
& \text { lac } \\
& \text { xyl- } \\
& \text { malt }
\end{aligned}
$$

$$
\begin{gathered}
\text { Maker } \\
\text { transduced }
\end{gathered}
$$

pro
tryp
leuc
isol
cys

arg
phe
gal
lac
xyl
malt

Frequency per phage adsorbed

$\mathbf{2 . 0} \times 10^{-7}$ $4.4 \times 10^{-7}$ $2 \cdot 2 \times 10^{-7}$ $1.3 \times 10^{-6}$ $2 \cdot 8 \times 10^{-7}$

$2 \cdot 3 \times 10^{-8}$ $3.0 \times 10^{-8}$ $3 \cdot 3 \times 10^{-8}$ $2.9 \times 10^{-8}$ $2 \cdot 0 \times 10^{-8}$ $1.7 \times 10^{-8}$

The transduction system. Log and stationary cultures are equally suitable for transduction experiments, but the former must be concentrated in order to obtain a moderate number of transductants per plate. For convenience, therefore, stationary cultures were used. As seen in Table 5, the number of transductants was approximately the same in the phage multiplicity range of 1-10, but it decreased when the multiplicity was reduced to $\mathbf{0} \cdot \mathbf{1}$. In unpublished experiments, using cultures concentrated tenfold so that the effects of phage multiplicities between 3.0 and 0.01 could be studied, the number of transductants was approximately the same except for a marked decrease when the multiplicity was reduced from $0 \cdot 1$ to 0.01 (Green, 1965).

These results differ from those reported for the $\mathbf{P} 22$ transduction system. Zinder (1953) reported that the number of Salmonella typhimurium transductants rises 
linearly with phage P22 multiplicities up to 10. It has been reported for the phage $\mathbf{P} 1$ transduction system that the frequency of transduction is a linear function of the P1 titre (Lennox, 1955). The data in Table 5 shows that this is not the case with the $\Phi$ 04-CF transduction system. In fact, the frequency of transduction is higher at the lower phage multiplicities (or titres). This increase is attributable to the fewer phage particles adsorbed per transductant.

Like phages P22 and P1, $\Phi$ 04-CF can transduce a variety of genetic markers. The list of markers transduced is shown in Table 6 .

In order to determine whether transduction was always accompanied by lysogenization, transduction experiments were run using a double auxotroph (tryp ${ }^{-}$, $m e t^{-}$) at a multiplicity of $0 \cdot 1$. This low multiplicity was chosen to lessen the chance of carrying over excess phage when checking for lysogenization. After the adsorption period, the phage-bacterium mixture was incubated with phage antiserum sufficient to inactivate greater than $99 \%$ of unadsorbed phage, and then centrifuged at $5^{\circ}$ to spin down the bacteria. After a series of such treatments the cells were resuspended in saline and plated on media selective for methionine transductants. The transductants were then picked, grown in broth, chloroform treated, and spotted on a soft agar seeded with bacteria susceptible to $\Phi$ 04-CF. A strain of Escherichia coli serotype 04 (labelled z 20), which adsorbs $\Phi$ 04-CF but can neither lyse nor become lysogenic, was also used in these experiments. As seen in Table 7, all 150 transductants tested were lysogenic. The fact that the $\mathrm{z} 20$ transductants were negative indicates that there was no extensive mechanical carry over of phage into the broth. However, the possibility of secondary lysogenization of the phagesusceptible auxotroph during one of the procedures subsequent to transduction cannot be excluded.

Table 7. Test for lysogenization of transductants at a $0 \cdot 1$ phage multiplicity

The recipients were concentrated $10 \times$ overnight.

$\begin{array}{lcc}\text { Number of } \\ \text { Mutant strains } & \begin{array}{c}\text { Number of } \\ \text { transductants } \\ \text { tested }\end{array} & \begin{array}{c}\text { broth cultures } \\ \text { containing } \\ \text { phage }\end{array} \\ \text { CF 2004-6 } \text { tryp }^{-} \text {met }^{-} & 150 & 150 \\ \text { z20 } \text { met }^{-} & 50 & 0\end{array}$

Strain CF 2004-6, a female. We were curious to see whether CF 2004-6 was sexually competent with $\mathrm{x} 12$ strains of Escherichia coli. If so, it would be possible to study genetic homology between these two distinct strains of $\boldsymbol{E}$. coli using the 04-CF or P1 transducing phages. Similar studies are being conducted with salmonella and $\boldsymbol{E}$. coli using P22 phage (see Discussion).

In mating experiments with donor strains of $\mathrm{K}$ 12, CF 2004-6 behaves as a recipient. This was proved by an experiment patterned after that described by Hayes (1952) to establish sexual polarity among $\mathrm{k} 12$ strains. The results are recorded in Table 8. Plating the mating mixture on agar containing streptomycin eliminated the recombinants when the CF 2004-6 strain was susceptible to the antibiotic. Of 50 recombinants isolated at random, all were susceptible to $\Phi$ 04-CF, and 44 were agglutinated by anti-04 serum. The six failures could be due to an inadequate heating procedure used to remove the envelope $(\mathbf{K})$ antigens which interfere with 
$O$ agglutination. In unpublished experiments a clear plaque (virulent) mutant of Ф 04-CF was substituted for the streptomycin, and it similarly eliminated the recombinants. These results prove that the recombinants on the selective media were CF 2004-6.

Several attempts have been made to obtain recombinants in mating experiments between CF 2004-6 and $\mathrm{F}^{-}$strains of Escherichia coli $\mathrm{K} 12$. None has been found. Brinton (1965) reported a good correlation between the presence in bacteria of the $F$ episome and susceptibility to male specific phage. Phage f2, a male specific phage (Loeb \& Zinder, 1961), does not grow on or adsorb to cF 2004-6. These negative findings support the view that cF 2004-6 is strictly a female strain, devoid of the F episome and donor ability.

Table 8. Recombinants per $0.3 \mathrm{ml}$. resulting from crosses between streptomycin susceptible (Str-s) and resistant (Str-r) strains of $\boldsymbol{E}$. coli $w_{1895 \text { lac }^{+} \text {met }^{-} \text {, and }}$ CF 2004-6 lac $^{+}$met $^{+}$, as selected on minimal lactose agar $(M L)$

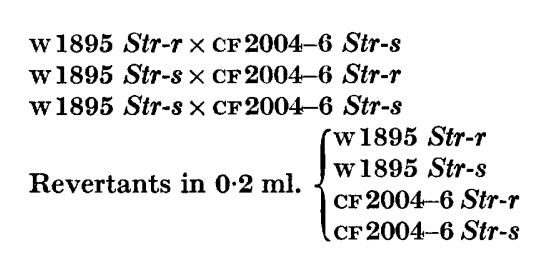

ML
$2 \cdot 3 \times 10^{4}$
$4 \cdot 8 \times 10^{4}$
$3 \cdot 4 \times 10^{4}$
0
0
1
2

$M L+$ streptomycin
0
$5 \cdot 1 \times 10^{4}$
0
0
0
0
0

In preliminary experiments it has been shown that there is a gradient of transmission of multiple markers from w 1895 and other Hfr donors to polyauxotrophic mutants of CF 2004-6. This conjugation system is currently being investigated.

\section{DISCUSSION}

Characterization of phage 04-CF was of interest because it had first been detected in a continuous flow culture mixture of Escherichia coli 04 and $E$. coli 0127 only after the 21st day (Spaulding et al. 1964). The indicator strain (CF 2004-6) for $\Phi$ 04-CF was also isolated from a sample of the same CF culture which yielded the phage. This phage has been characterized and shown to be specific for $\boldsymbol{E}$. coli serotype 04 . Neither $E$. coli 0127 nor 04 seemed at the time to be lysogenic for this phage. However, after incubating $E$. coli 04 in an Erlenmeyer flask culture for 3 days, a phage producing a tiny plaque on CF 2004-6 was isolated. This phage (labelled $\Phi$ X 1) is serologically related to $\Phi$ 04-CF by the spot testing method (unpublished data). The exquisite specificity of $\Phi 04-C F$, and the isolation of a serologically related phage from $E$. coli 04, suggests that $E$. coli 04 is the source of $\Phi 04-C F$. The characteristics of $\Phi \mathrm{X} 1$ will eventually be compared with $\Phi$ 04-CF since it may be that $\Phi \mathrm{X} 1$ is a mutant of $\Phi 04-\mathrm{CF}$ or vice versa.

Early in these investigations it was discovered that $\Phi$ 04-CF is another generalized transducing phage. It does not require additional $\mathrm{Ca}^{2+}$ for adsorption as does the other Escherichia coli transducing phage P1 (Lennox, 1955), nor does it seem to have a long tail like P1 (Bertani, 1958). In addition, the results of host range and neutralization studies show it to be distinct from P1 and P22, the generalized transducing phage of Salmonella typhimurium. 
It resembles the specialized transducing phage lambda, in being readily inducible by ultraviolet irradiation. The $25 \%$ induction of lysogenic CF 2004-6 to produce infective centres is not so great as the $95 \%$ induction reported for lambda (Weigle \& Delbruck, 1951). However, $\Phi$ 04-CF is more inducible than P22 as reported by Levine (1961) who used mitomycin $\mathrm{C}$ which mimics the inducing action of ultraviolet light. He observed an induction of up to $91 \%$ of the lysogenic Salmonella typhimurium cells surviving exposure to mitomycin C. On this basis, lysogenic CF 2004-6 is more than $99 \%$ inducible. Another specialized transducing phage, $\Phi 80$ (Matsushiro, 1961), has also been shown to be readily inducible by ultraviolet light.

The transduction system of $\Phi$ 04-CF appears to be similar to the generalized transducing systems mediated by phages P1 (Lennox, 1955) and P22 (Zinder \& Lederberg, 1952) in that the frequencies of transduction for a variety of markers ranged from $10^{-6}$ to $10^{-8}$. However, these transduction frequencies and the absolute number of transductants appearing per plate do not appear to be linearly related to the phage multiplicities used. The reason for these results is not clear.

Occasional transductants mediated by phage P22 have been found to be nonlysogenic (Stocker, Zinder \& Lederberg, 1953). Adams \& Luria (1958) reported that transductions by $\mathbf{P} 1$ at phage multiplicities of less than one are generally not accompanied by lysogenization. It is to be noted that these conclusive results with phage P1 were obtained by using selective medium lacking $\mathrm{Ca}^{2+}$ which $\mathrm{Pl}$ needs for adsorption. Non-lysogenic transductants mediated by $\Phi$ 04-CF have not been found, but it is difficult to eliminate secondary lysogenization.

Dettori, Maccacaro \& Piccinin (1961) and Hakura, Otsuji \& Hirota (1964) reported the isolation of phages specific for $\mathrm{F}^{-}$strains of $E$. coli $\mathrm{K} 12$, but no mention was made of the transducing ability of these phages. Though $\Phi$ 04 $-\mathrm{CF}$ is a transducing phage for a female strain of $E$. coli 04, this sexual characteristic is not necessary for transduction. In fact, $\Phi$ 04-CF can transduce markers into a recently isolated donor strain of CF 2004-6 (unpublished). In this respect phage 04-CF is analogous to $\mathbf{P} 22$ which is a transducing phage for Salmonella typhimurium regardless whether it is a recipient in matings with $\boldsymbol{E}$. coli $\mathrm{k} 12$ strains, or not. The interest in CF 2004-6 being a female strain is that transduction by phage can now be used to check the extent of genetic homology within $E$. coli strains (Zubrzycki \& Spaulding, 1965) as was done for $E$. coli and salmonella (Zinder, 1960; Demerec \& Ohta, 1964) using phage P22.

Portions of this work were abstracted from a Master's Thesis by Judith G. Green, Temple University, Philadelphia (1965) who received support from a predoctoral award and a training grant (GM 983) of the Public Health Service. This investigation was also supported in part by Public Health Service research grants AI 02722 and AI 06581. We are grateful to the following persons: Dr L. S. Baron, Walter Reed Institute for Research, for many of the bacterial strains used in these experiments; Dr N. Yamamoto, Fels Institute, Temple University for phage strains and his constant interest in the work: Mrs Joan H. Lanphear for her technical assistance. 


\section{REFERENCES}

Adams, M. H. (1959). Bacteriophages. New York: Interscience Publishers, Inc.

Adams, J. N. \& LuRIA, S. E. (1958). Transduction by bacteriophage P1: abnormal phage function of the transducing particles. Proc. natn. Acad. Sci., U.S.A. 44, 590.

Bertani, G. (1958). Lysogeny. Advanc. Virus Res. 5, 151.

Brinton, C. C. (1965). The structure, function, synthesis and genetic control of bacterial pili and a molecular model for DNA and RNA transport in Gram negative bacteria. Trans. N.Y. Acad. Sci. 27, 1003.

Demerec, M. \& Ohta, N. (1964). Genetic analyses of Salmonella typhimurium \& Escherichia coli hybrids. Proc. natn. Acad. Sci., U.S.A. 52, 317.

Dettori, R., Maccacaro, G. A. \& Piccinin, G. L. (1961). Sex specific bacteriophages of Escherichia coli к 12. Giorn. Microbiol. 9, 141.

GrEen, J. (1965). Characterization of the transduction system of phage $\Phi$ 04-CF. M.S. Thesis, Temple University, Philadelphia, Pennsylvania.

Guthrie, G. D. \& Sinsheimer, R. L. (1963). Observations on the infection of bacterial protoplasts with the deoxyribonucleic acid of bacteriophage $\Phi$ X174. Biochem. biophys. Acta 72, 290.

Hakura, A., Otsuji, N. \& Hirota, Y. (1964). A temperate phage specific for female strains of Escherichia coli $\mathbf{~ 1 2 . ~ J . ~ g e n . ~ M i c r o b i o l . ~ 3 5 , ~} 69$.

HAYES, W. (1952). Recombination in Bacterium coli $\mathrm{k-12}$ : undirectional transfer of genetic material. Nature, Lond. 169, 118.

LEDERBERG, J. (1950). Isolation and characterization of biochemical mutants of bacteria. Meth. med. Res. 3, 5.

LENNox, E. S. (1955). Transduction of linked genetic characters of the host by bacteriophage Pl. Virology 1, 190.

LEVINE, M. (1961). Effect of mitomycin $\mathrm{C}$ on interaction between temperate phages and bacteria. Virology 13, 493.

Loeb, T. \& Zinder, N. D. (1961). A bacteriophage containing RNA. Proc. natn. Acad. Sci., U.S.A. 47, 282.

Matney, T. S. \& AchenbaCh, N. E. (1962). A comment on the fertility of F2 donor types of $E$. coli к 12. Biochem. biophys. Res. Communs. 9, 285.

Matsushiro, A. (1961). Isolation of UV-inducible temperate phage $\Phi$ 80. Biken's J. 4, 138.

Postic, B. \& Finland, M. (1961). Observations on bacteriophage typing of Pseudomonas aeruginosa. J. clin. Invest. 40, 2064.

SchNeIDER, W. C. (1957). Determination of nucleic acids in tissues by pentose analysis. Meth. Enzym. 3, 680.

Spaulding, E. H., Zubrzycki, L. \& Lanphear, J. H. (1964). Continuous-flow culture studies with mixed strains of Escherichia coli: isolation of a lytic factor. Bact. Proc. p. 68.

Stocker, B. A. D., Zinder, N. D. \& Lederberg, J. (1953). Transduction of flagellar characters. J. gen. Microbiol. 9, 410.

Weigle, J. J. \& DelbrucK, M. (1951). Mutual exclusion between an infecting phage and a carried phage. J. Bact. 62, 301.

ZINDER, N. D. (1953). Infective heredity in bacteria. Cold Spring Harbor Symp. quant. Biol. 18, 261.

ZiNDER, N. D. (1960). Hybrids of Escherichia and Salmonella. Science 131, 813.

ZiNDER, N. D. \& LeDerberG, J. (1952). Genetic exchange in Salmonella. J. Bact. 64, 679.

Zubrzycki, L. \& Spaulding, E. H. (1965). Genetic heterogeneity between Escherichia coli strains. Bact. Proc. p. 142. 